\title{
Statistical Analysis of Literature Research on Preschool Education Informatization
}

\author{
Yutong Fang ${ }^{a}$, Xin Wang ${ }^{b}$ and Mengqiu Cai ${ }^{\mathrm{c}}$ \\ School of Physics and Microeletronics Science, Hunan University, Changsha 410082, Hunan, \\ China. \\ a fyutong@hnu.edu.cn, b hudawangxin@qq.com, ${ }^{c}$ mqcai@hnu.edu.cn
}

Keywords: Pre-school education; Informatization; literature statistics.

\begin{abstract}
The method of document metrology and content analysis are applied in preschool education informatization research. The study shows that, from the publication of the age distribution, authors backgrounds, publishing institutions and research content, the overall level in preschool education informatization research is going up but not enough in depth. High-level research-group, typical research model and instruction to the research are urge needed.
\end{abstract}

\section{Introduction}

Education information has become a hot spot in education research in recent years. The rapid development of education information makes Informa ionization of preschool education become inevitable. If preschool education should be transformed into the real development of children, it is necessary to create an environment suitable for education informatization and to guide children In line with their physical and mental characteristics of the educational environment, toward the direction of education development. State promulgated a series of policies and regulations also provide opportunities and challenges for the development of pre-school education information. In 2012, the Ministry of Education issued the "Development Plan for the decade of Education Informatization (2011-2020)", launched the "three links and two platforms" and the "full coverage of Digital Education Resources at Teaching points"; on 2016, the Ministry of Education issued the 13th Five-Year Plan of Education Informatization. "by 2020, we will have basically completed the goal of 'Learning for all,"' We can learn everywhere, we can learn from time to time. This paper points out some problems in the integration of preschool education and information technology and puts forward the prospect of information research on preschool education in the future. The purpose is to find out the research situation of preschool education informatization, and to provide reference for the research of preschool education informatization.

\section{Selection of Research Materials}

This paper selects the related papers of Chinese online preschool education information as the source of analysis samples and searches them with keywords. Use "preschool education" with "information", "preschool education" with "information technology", "early childhood education" with "information technology", "early childhood education" with "information technology" for retrieval [2] and allow synonyms to be expanded. The article is published until December 1 st 2017 for advanced retrieval. A total of 307 papers were searched out. 4 papers with little relevance to the contents of this study were excluded, and 303 papers were selected as samples for the analysis of the contents of this study.

\section{Statistical Results and Analysis}

\subsection{Distribution of Time and Quantity of Publication}

Statistical analysis of the time distribution of papers published, we can understand the research situation and the speed of development of such articles in time. From the number of published 
documents over the years, the literature on pre-school education information research basically shows an upward trend. In line with the development trend of informatization in the whole field of education in China. In a series of institutional settings, the number of papers published in 2014 and 2017 has reached a high level. During the peak period, until 2011, the number of scientific research was kept below 10 per year, and increased year by year in 2011, with the overall trend (the deadline for collection of documents December 1st 2017), especially in the past four years, The annual average number of papers issued is more than 40, indicating that the number of people studying the informatization of preschool education in China has increased, and the degree of concern about it has also increased. (see Table 1)

Table 1. Annual distribution of relevant literature

\subsection{Institutional and Geographical Distribution of Literature Authors}

From the point of view of the institution where the authors of the research documents are located, this research is not a "patent" of higher education, but more of a practical study of preschool teachers, which in fact has something to do with the discipline characteristics of preschool education itself. It is mainly divided into three parts, some of which come from kindergarten. Some of them are colleges and universities. In all articles, 197 are written in kindergartens, 44 in specialized colleges, 52 in undergraduate schools, and 10 in other articles. The research of pre-school education informatization in pre-school education has been increasing.

From the distribution of the region where the authors of the literature are located, we can understand the degree of attention, the degree of development and the research level of the information development of preschool education in various places. The level of research on the informatization of preschool education in China is not uniform. East China has the most literature on pre-school information, followed by Northwest China and Central China. At present, the information situation of preschool education is not optimistic. In the environment of fierce competition of subject resources, it is very difficult to receive "special treatment" for the subject of preschool education. There are still some differences between the promulgation of policies and regulations by the state and the concrete implementation and promotion. (see Table 2)

Table 2. Regional distribution of the authors of literature

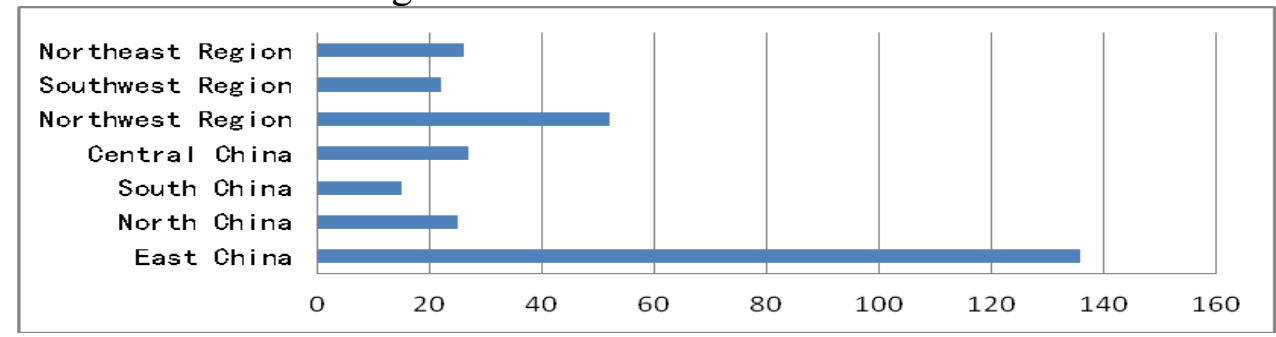

\subsection{Analysis on the Research Content of Pre-School Education Informatization}

The paper takes the information resources, the information network, the information technology application, the information technology and the industry as the reference standards. Grasp the viewpoints and purposes stated in the literature, use content analysis method to compare, analyze and summarize the obtained documents, determine basic research, applied research, management and construction, resource development, cost-effectiveness, the evaluation system and personnel information literacy are classified as the analysis framework of preschool education informatization. At the same time, in order to grasp the content of each document more finely, the first-class category is divided into two categories. The classification is based mainly on the categories designed in the literature referring to the relevant research on educational informatization. See Table 3 for details: 
Table 3. Content Coding System Tables and Results Statistics

\begin{tabular}{|c|c|c|c|c|}
\hline First Class Category & Secondary Category & Encoded & Number & Percentage \\
\hline \multirow{3}{*}{ Fundamental Research } & Basic concepts, Characteristics, Theory & A1 & 10 & \multirow{3}{*}{$38 \%$} \\
\hline & Status Survey, Development Strategy & A2 & 39 & \\
\hline & Significance, Role and Rrends & A3 & 66 & \\
\hline \multirow[b]{2}{*}{ Application Research } & Course Integration & B1 & 44 & \multirow[b]{2}{*}{$46 \%$} \\
\hline & $\begin{array}{l}\text { Technology, Ideas andmethod } \\
\text { applications }\end{array}$ & $\begin{array}{l}\mathrm{D} 1 \\
\mathrm{~B} 2\end{array}$ & $\begin{array}{l}44 \\
94\end{array}$ & \\
\hline \multirow{2}{*}{$\begin{array}{l}\text { Management and } \\
\text { Construction }\end{array}$} & Digital Campus & $\mathrm{C} 1$ & 5 & \multirow{2}{*}{$2 \%$} \\
\hline & Institutional research & $\mathrm{C} 2$ & 2 & \\
\hline \multirow{4}{*}{ Resource Construction } & Website, System Development & & & \multirow{4}{*}{$11 \%$} \\
\hline & Status, Influencing Factors and & D1 & 6 & \\
\hline & Development Strategy & D2 & 20 & \\
\hline & $\begin{array}{c}\text { Resource Construction Theory and } \\
\text { Practice }\end{array}$ & D3 & 8 & \\
\hline Personnel Training & $\begin{array}{l}\text { Information literacy and } \\
\text { Countermeasures }\end{array}$ & E1 & 7 & $2 \%$ \\
\hline $\begin{array}{l}\text { Cost-benefit and } \\
\text { Evaluation }\end{array}$ & & F1 & 2 & $1 \%$ \\
\hline
\end{tabular}

From the content of the study scale, at present study on preschool education informatization mainly focus on basic research and applied research, one of the largest application, accounted for $46 \%$ of the total sample; second is the basis of the total $38 \%$; and the preschool education information resources construction of 34 , accounting for the total sample of $11 \%$; the management of construction and personnel training literatures are $2 \%$; another concern is cost effective for preschool teaching information, research literature evaluation system is only 2 . At most, the applied research shows that most scholars have begun to pay more and more attention to the practicability and effectiveness of the research and pay attention to the effect of information technology on preschool teaching. The basic research focuses on the meaning, function, trend and so on. On the other hand, there are few literatures on management construction and talent cultivation, which shows that the attention to talent training and management construction is not enough, and the cost benefit, there are only 2 papers on evaluation system, which reflects the lack of evaluation system in the research of preschool education informatization. It is a problem we must face, but few scholars are paying attention to it.

\section{Epilogue}

First, from the research content analysis, the preschool education information personnel training, the management and the construction is relatively few, lacks to the preschool teacher informationization ability cultivation, although the applied research aspect literature is relatively more. To some extent, it also stems from the marginalization of preschool education itself.

Second, through the study of the authors of the literature, it is found that most of the researchers are front-line preschool education workers, with rich teaching practice experience, but the research is scattered and not deep enough. And the implementation and application of the case does not play a typical representative, so we should pay attention to the promotion and communication of typical cases.

Fourth, from the perspective of the development gap between different regions, it also warned that the management of preschool education should be adapted to local conditions, to promote the balanced development of informatization and coordinate application. 


\section{References}

[1]. Ten Years Development Plan of Educational Informatization (2011-2020) [J]. Chinese Educational Informatization,2012, (08):3-12.

[2]. Wang Ji. The Present Situation and Countermeasures of Preschool Education Informatization[J]. Chinese Educational Technology Equipment,2011, (36)126-127.

[3]. Zhang Yuan.Twenty Years of Preschool Education Research in China: A Bibliometric Analysis Based on "Pre-school Education Research"[J]. Preschool EducationResearch,2014, (01):3-5.

[4]. Zhu Wenhui.Current Situation of Information Construction and Application of Preschool Education in China[J]. E-education Research,2013(10):42-43.

[5]. Tang Yewei. A Summary of Microcores Research Based on Content Analysis[J].China Educational Technology,2015, (4):74-80. 